\title{
Pengaruh Metode Ekstraksi Terhadap Kadar Total Fenolik dan Kadar Total Flavonoid Daun Talas (Colocasia esculenta L.)
}

\section{The influence of a method of the extraction of against the level of the total content of phenolic and total flavonoid leaves taro (Colocasia esculenta $L_{\text {.) }}$}

\author{
Septiana Laksmi Ramayani ${ }^{1}$, Devi Hildhania Nugraheni ${ }^{1}$, Antonius Robertin Evan \\ Wicaksono ${ }^{1}$ \\ septianaLR@gmail.com \\ ${ }^{1}$ Program Studi D3 Farmasi, Politeknik Katolik Mangunwijaya, Semarang
}

Riwayat Artikel: Dikirim Desember 2020; Diterima Februari 2021; Diterbitkan Maret 2021

\begin{abstract}
Abstrak
Daun talas (Colocasia esculenta L.) diketahui dapat digunakan sebagai antidiabetes, karena adanya kandungan senyawa bioaktif senyawa fenolik dan flavonoid. Aktivitas farmakologis suatu ekstrak bergantung pada kadar senyawa aktif yang terkandung, semakin besar kadar senyawa maka semakin tinggi pula aktivitasnya. Metode ekstraksi mempengaruhi konsentrasi atau hilangnya efek terapi dari simplisia karena beberapa simplisia bersifat relatif tidak stabil dan dapat terurai. Tujuan penelitian ini adalah mengetahui pengaruh perbedaan metode ekstraksi terhadap kadar total senyawa fenolik dan kadar total senyawa flavonoid ekstrak daun talas. Ekstraksi daun talas menggunakan pelarut etanol $96 \%$ menggunakan metode maserasi, Microwave Assisted Extraction (MAE) dan sokletasi. Penetapan kadar total senyawa Fenolik menggunakan metode Folin Ciocalteau dengan baku pembanding asam galat. Penetapan kadar total flavonoid menggunakan metode kolorimetri dengan pereaksi $\mathrm{AlCl}_{3}$ dan baku pembanding kuersetin. Metode ekstraksi berpengaruh signifikan terhadap kadar total fenolik dan kadar total flavonoid ekstrak daun talas dengan nilai $p<0,05$. Kadar total fenolik dan kadar total flavonoid tertinggi pada metode ekstraksi sokletasi yaitu sebesar 10,39 mgGAE/g ekstrak dan 12,44 mgKE/g ekstrak.

Kata kunci: daun talas, kadar total fenolik, kadar total flavonoid, metode ekstraksi
\end{abstract}

\begin{abstract}
Leaves taro ( colocasia esculenta i. Known) can be used as an antidiabetic drug, due to the compound and flavonoid phenolic bioactive compound. Pharmacological activity an extract dependent on the active compounds contained, more compound higher the levels the more activity. Method extraction affecting concentration or loss of effect of simplicia therapy as some simplicia is relatively unstable and we. The purpose of this research is to know influence different calculation methods extraction to total levels phenolic compounds and total levels flavonoid compounds taro extract leaves. The extraction of leaves taro uses a solvent ethanol $96 \%$ uses the method maceration, microwave-assisted extraction (MAE), and soxhletasion. The determination of the total content of phenolic compounds uses the method Folin Ciocalteau by an exchange of a standard for comparison
\end{abstract}


of gallic acid. The determination of the level of the total flavonoid uses the method colorimetry with reagent $A / C l 3$ by an exchange of a standard for comparison of quercetin. A method of the extraction of significant impact on the level of the total flavonoid content of phenolic and total extract leaves taro with the value of $p<0,05$. The total content of phenolic and total flavonoid highest levels on the method the extraction of soxhletasion which is $10,39 \mathrm{mgGAE} / \mathrm{g}$ extract and $12,44 \mathrm{mgKE} / \mathrm{g}$. extract.

Keywords : Leaves taro, total phenolic content, total flavonoid content, methods extraction

\section{Pendahuluan}

Tanaman talas (Colocasia esculenta L.) merupakan tanaman yang berasal dari daerah tropis salah satunya adalah Indonesia. Masyarakat Indonesia pada umumnya sering menggunakan tanaman talas pada bagian umbinya yaitu sebagai sumber karbohidrat (Richana, 2012). Tanaman talas selain sebagai sumber karbohidrat diketahui juga dapat digunakan sebagai antidiabetes, yaitu pada bagian daunnya. Kumawat et al (2010), menyebutkan bahwa ekstrak daun talas pada dosis $450 \mathrm{mg} / \mathrm{kg}$ mampu menurunkan kadar gula darah sebesar $175 \mathrm{mg} / \mathrm{dl}$. Tendean et al., (2017) menyebutkan bahwa ekstrak daun talas memiliki pengaruh terhadap regenerasi jaringan pancreas. Perbaikan pulau Langerhans yang diikuti dengan terjadinya regenerasi pada pulau Langerhans disebabkan karena adanya kandungan senyawa bioaktif senyawa fenolik dan flavonoid.

Ramayani et al., (2000) menyebutkan bahwa kadar senyawa fenolik daun talas adalah sebesar 8.11 mgGAE/g ekstrak dan kadar senyawa flavonoid daun talas sebesar 4,43 $\mathrm{mgKE} / \mathrm{g}$ ekstrak. Aktivitas farmakologis suatu ekstrak bergantung pada kadar senyawa aktif yang terkandung, semakin besar kadar senyawa maka semakin tinggi pula aktivitasnya. Metode ekstraksi mempengaruhi konsentrasi atau hilangnya efek terapi dari simplisia karena beberapa simplisia bersifat relatif tidak stabil dan dapat terurai (Usman, 2019). Metode ekstraksi dibedakan menjadi 2 yaitu ekstraksi dingin (maserasi) dan ekstrkasi panas (sokletasi). Microwave Assisted Extraction (MAE) merupakan modifikasi dari maserasi yang menggunkan bantuan gelombang mikro sehingga dapat membuat ekstrkasi lebih efektif dan efisien (Kusnadi, 2017). Pengaruh panas pada proses ekstraksi akan mempengaruhi stabilitas senyawa. Tujuan penelitian ini adalah mengetahui pengaruh perbedaan metode ekstraksi terhadap kadar total senyawa fenolik dan kadar total senyawa flavonoid ekstrak daun talas.

\section{Metode Penelitian}

Alat

Alat yang digunakan adalah kertas saring, toples kaca, botol coklat, neraca analitik (Mettler Toledo), moisture analyzer (Ohaus), waterbath, beakerglass (Pyrex), labu takar (Pyrex), tabung reaksi (Pyrex), pipet volume (Pyrex), pipet tetes, pipet filler, shaker, vial, stopwatch, pengaduk gelas, gelas ukur (Pyrex), cawan porselen (Pyrex), corong kaca (Pyrex), alat soklet, kuvet, termometer, microwive (Metroweath), klem, statif, labu alas bulat (Pyrex), dan spektrofotometer UV-Vis (MINI Shimadzu 1240).

Bahan

Bahan yang digunakan adalah serbuk daun talas Materia Medica Batu, pelarut etanol pro analisa, etanol 96\%, larutan $\mathrm{FeCl}_{3}, \mathrm{HCl}$ pekat, serbuk Mg (Merck), metanol pro analisa, aquadestilata, asam galat, kuersetin, reagen Folin-Ciocalteau, dan larutan $\mathrm{Na}_{2} \mathrm{CO}_{3} 1 \mathrm{M}$, $\mathrm{AlCl}_{3} 10 \%, \mathrm{CH}_{3} \mathrm{COOH} \mathrm{5 \%}$

\section{Tahapan Penelitian}

\section{Ekstraksi}

Ekstraksi daun talas dilakukan dengan menggunakan $40 \mathrm{~g}$ serbuk dan $400 \mathrm{~mL}$ etanol 96\%. Metode ekstraksi yang digunakan yaitu maserasi, Microwave Assisted Extraction (MAE) dan sokletasi.

a. Maserasi

Maserasi dilakukan selama 3x24 jam, tiap 24 jam dilakukan pengadukan menggunakan shaker selama 1 jam, ekstrak disimpan terlindung dari cahaya matahari. Hasil rendaman disaring menggunakan kertas saring hingga memperoleh filtrat. 
b. MAE

Ekstraksi menggunakan microwive pada suhu $50^{\circ} \mathrm{C}$ dengan waktu 2 menit, diradiasi setiap 15 detik didiamkan selama 2 menit kemudian disaring menggunakan kertas saring dan diperoleh filtrat.

c. Sokletasi

Ekstraksi dilakukan dengan alat soklet pada suhu $50-60^{\circ} \mathrm{C}$ selama 4 jam hingga pelarut pada tube extractor tampak jernih.

Masing-masing filtrat yang dihasilkan kemudia dipekatkan dengan menggunakan waterbath pada suhu $<60^{\circ} \mathrm{C}$ sampai terbentuk ekstrak kental.. ekstrak yang dihasilkan selanjutnya dilakukan control kualitas meliputi organoleptis, susut pengeringan dan perhitungan rendemen dengan rumus sebagai berikut :

Rendemen $=\frac{\text { Berat Ekstrak }}{\text { Berat Simplisin }} \mathrm{X} 100 \%$

\section{Uji Kualitatif}

a. Senyawa fenolik

Uji kualitatif dilakukan dengan menggunakan reagen $\mathrm{FeCl}_{3}$ 1\%. Masingmasing larutan uji $(0,1 \mathrm{~g}$ ekstrak dalam $6 \mathrm{~mL}$ etanol 96\%) ditambahkan 2 tetes reagen $\mathrm{FeCl}_{3} \quad 1 \%$. Terbentuknya warna hijau, merah, ungu, biru dan hitam pekat pada larutan uji menunjukkan adanya senyawa fenolik (Harbone, 1987),

b. Senyawa flavonoid

Uji kualitatif dilakukan dengan uji Shinoda. Masing-masing larutan uji $(0,1 \mathrm{~g}$ ekstrak dalam $6 \mathrm{~mL}$ etanol 96\%) ditambahkan $1 \mathrm{~mL} \mathrm{HCl}$ pekat dan 0,5 gram serbuk $\mathrm{Mg}$. terbentuknya warna kuning atau jingga menunjukkan adanya senyawa flavonoid (Harbone, 1987).

\section{Uji Kuantitatif}

a. Senyawa fenolik

Sebanyak 1,0 mL larutan uji (250 ppm) dan larutan baku asam galat $(20,30,40,50$ dan $60 \mathrm{ppm})$ dimasukkan dalam tabung reaksi, kemudian ditambahkan $5 \mathrm{~mL}$ reagen Follin Ciocalteau (1:10) dan $4 \mathrm{~mL}$ larutan $\mathrm{Na} 2 \mathrm{CO} 3$ 1M. Larutan diinkubasi selama 25 menit dan kemudian diukur absorbansinya pada Panjang gelombang $748,20 \mathrm{~nm}$. Berdasarkan persaman kurva kalibrasi selanjutnya ditentukan kadar total fenolik dengan persamaan (2).

\author{
Kadar Total Senyawa Fenolik $=\frac{\text { e. } \nabla \text {-糔 }}{g}(2)$ \\ Keterangan : \\ $\mathrm{c}=$ konsentrasi fenolik (nilai $\mathrm{x}$ ) \\ $\mathrm{v}=$ volume ekstrak yang digunakan $(\mathrm{mL})$ \\ $\mathrm{fp}=$ faktor pengenceran \\ $\mathrm{g}=$ berat sampel yang digunakan $(\mathrm{g})$
}

b. Senyawa flavonoid

Sebanyak 1,0 mL larutan uji (1000 ppm) dan larutan baku asam galat $(20,40,60,80$ dan $100 \mathrm{ppm}$ ) dimasukkan dalam tabung reaksi, kemudian ditambahkan $1 \mathrm{~mL}$ $\mathrm{AlCl}_{3} 10 \%$ dan $8 \mathrm{~mL}$ asam asetat $5 \%$ lalu dihomogenkan. Masing-masing larutan didiamkan selama 14 menit dan diukur absorbansinya pada Panjang gelomang 413,90 nm. Berdasarkan persaman kurva kalibrasi selanjutnya ditentukan kadar total fenolik dengan persamaan (3).

$$
\begin{aligned}
& \text { Kadar Total Senyawa Flavonoid }=\frac{\mathrm{c} \cdot \mathrm{v} \cdot \mathrm{p}}{\mathrm{g}}(2) \\
& \begin{aligned}
\text { Keterangan : } \\
\mathrm{c} \quad=\text { konsentrasi flavonoid (nilai } \mathrm{x}) \\
\mathrm{v} \quad=\text { volume ekstrak yang digunakan }(\mathrm{mL}) \\
\mathrm{fp} \quad=\text { faktor pengenceran } \\
\mathrm{g} \quad=\text { berat sampel yang digunakan }(\mathrm{g})
\end{aligned}
\end{aligned}
$$

\section{Analisa Data}

Kadar senyawa fenolik dianalisa secara statsistik menggunakan uji Kruskal Wallis dan dilanjutkan dengan uji Mann Whitney. Kadar senyawa flavonoid dianalisa secara statsistik menggunakan uji $A N N O V A$ dan dilanjutkan dengan uji Post-Hoc. Keduanya menggunakan taraf kepercayaan $95 \%$.

\section{Hasil dan Pembahasan}

Bagian tanaman talas yang digunakan adalah daun. Menurut (Ramayani et al., 2000) daun talas mengandung senyawa fenolik dan senyawa flavonoid lebih tinggi dibandingkan bagian tangkai dan umbi. Serbuk daun talas yang diperoleh berupa serbuk berwarna hijau, berbau khas dan tidak berasa. Susut pengeringan serbuk daun talas adalah 9,57\%.

Serbuk daun talas diekstraksi dengan menggunakan pelarut etanol 96\%. Senyawa fenolik dan flavonoid merupakan senyawa yang polar sehingga akan larut dalam pelarut polar, salah satunya etanol $96 \%$, sesuai dengan prinsip like dissolve like (Kemit et al., 2010). 
Metode maserasi, MAE dan sokletasi. Hasil kontrol kualitas ekstrak daun talas dapat dilihat pada Tabel 1.

Tabel 1. Kontrol Kualitas Ekstrak Daun Talas

\begin{tabular}{lccc}
\hline \multicolumn{1}{c}{ Parameter } & Maserasi & MAE & Sokletasi \\
\hline Organoleptis & Kental & Kental & Kental \\
$\begin{array}{l}\text { Bentuk } \\
\text { Warna }\end{array}$ & $\begin{array}{l}\text { Hijau } \\
\text { Kecoklatan }\end{array}$ & $\begin{array}{c}\text { Hijau } \\
\text { Kecoklatan }\end{array}$ & $\begin{array}{c}\text { Hijau } \\
\text { Kecoklatan }\end{array}$ \\
$\begin{array}{l}\text { Bau } \\
\text { Rasa }\end{array}$ & $\begin{array}{c}\text { Bau Khas } \\
\text { Pahit }\end{array}$ & $\begin{array}{c}\text { Bau Khas } \\
\text { Pahit }\end{array}$ & $\begin{array}{c}\text { Bau Khas } \\
\text { Pahit }\end{array}$ \\
\hline $\begin{array}{l}\text { Rendemen } \\
\text { (\%) }\end{array}$ & $12,03 \pm 1,07^{\mathrm{a}}$ & $14,05 \pm 1,03^{\mathrm{a}}$ & $20,69 \pm 0,90^{\mathrm{b}}$ \\
\hline $\begin{array}{l}\text { Susut } \\
\text { pengeringan } \\
\mathbf{( \% )}\end{array}$ & $2 \pm 0,01^{\mathrm{a}}$ & $1,95 \pm 0,02^{\mathrm{a}}$ & $3,95 \pm 0,02^{\mathrm{b}}$ \\
\hline
\end{tabular}

Ekstrak yang dihasilkan mengalami perubahan warna menjadi hijau kehitaman. Perubahan warna terjadi karena terjadinya reaksi oksidasi pada proses penguapan filtrat menjadi ekstrak kental. Rendemen tertinggi diperoleh pada metode ekstraksi sokletasi diikuti maserasi dan MAE. Metode ekstraksi berpengaruh signifikan pada jumlah rendemen yang dihasilkan. Pada metode maserasi dan MAE, perolehan rendemen tidak berpengaruh signifikan, karena memiliki prinsip kerja yang sama yaitu perendaman sehingga terjadi kejenuhan pelarut. Hasil serupa ditunjukkan dalam penelitian Puspitasari (2016) bahwa rendemen total ekstrak daun kersen menggunakan metode sokletasi lebih besar dibandingkan metode maserasi.

Uji kualitatif menunjukkan bahwa ekstrak daun talas pada ketiga metode ekstraksi positif mengandung senyawa fenolik dan flavonoid. Hasil positif ditunjukkan dengan terbentuknya warna hijau kehitaman dengan pereaksi $\mathrm{FeCl}_{3}$ 1\% dan terbentuknya warna jingga dengan pereaksi $\mathrm{HCl}$ pekat dan serbuk Mg. Reaksi uji kualitatif senyawa fenolik dan flavonoid dapat dilihat pada gambar 1 dan 2.

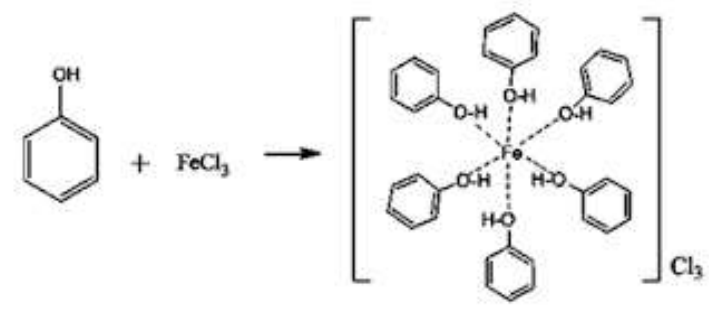

Gambar 1. Reaksi Kimia Antara Senyawa Fenol dengan $\mathrm{FeCl}_{3}$

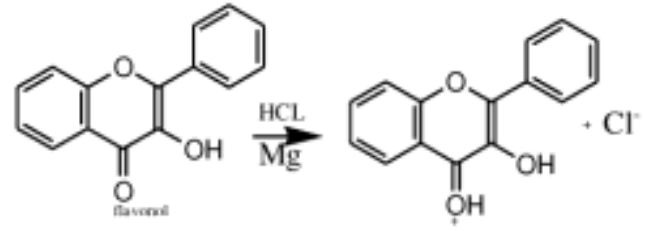<smiles>O=c1c(O)c(-c2ccccc2)oc2ccccc12</smiles>

Gambar 2. Reaksi Kimia Antara Senyawa Flavonoid dengan $\mathrm{HCl}$ dan serbuk $\mathrm{Mg}$

Uji kuantitatif kadar total senyawa fenolik dilakukan dengan metode Folin Ciocalteau. Reagen Folin-Cioucalteau hanya akan bereaksi pada suasana basa, sehingga akan terjadi perubahan dari senyawa fenol menjadi ion fenolat dengan penambahan $\mathrm{Na}_{2} \mathrm{CO}_{3} 1 \mathrm{M}$ (Ismail et al, 2012). Pereaksi Folin Ciocaltean mengoksidasi fenolat (garam alkali) atau gugus fenolik-hidroksi mereduksi asam galat heteropoli (fosfomolibdat - fosfotungstat) yang terdapat dalam pereaksi Folin-Cioucaltean menjadi suatu kompleks molybdemumtungsten (Blainski et al, 2013). Baku pembanding yang digunakan adalah asam galat.

Asam galat merupakan turunan asam hidroksibenzoat yang termasuk dalam golongan asam fenol sederhana, bersifat murni, stabil dan relatif lebih murah dibanding dengan standar lain (Lee et al., 2003). Persamaan regresi yang diperoleh adalah $\mathrm{y}=0,01 \mathrm{x}+0,0455$ dengan koefisien relasi $(\mathrm{R} 2)=0,9998$.

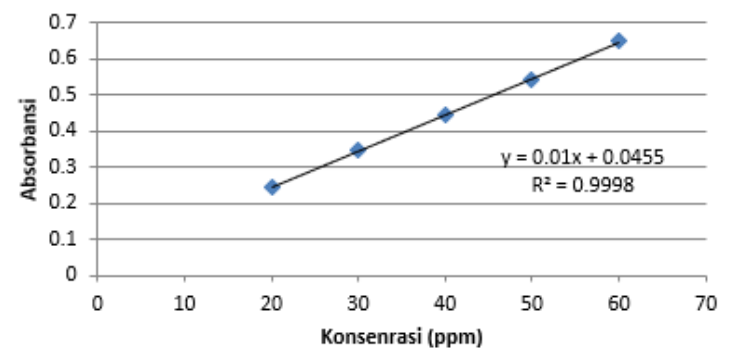

Gambar 3. Kurva Baku Asam Galat

Uji kuantitatif senyawa flavonoid dilakukan dengan metode kolorimetri komplementer dengan menggunakan reaksi pembentukan warna secara kompleks antara flavonoid dengan $\mathrm{AlCl}_{3}$. Penambahan reagen $\mathrm{AlCl}_{3}$ membentuk kompleks dengan gugus hidroksil keton atau orto dihidroksi sehingga memperpanjang gelombang kearah 
visible (Batokromik). Gugus keto pada atom C4 dan gugus hidroksi atom C-3 atau C-4 berdekatan dengan struktur flavon dan flavonol, sehingga metode ini dapat digunakan untuk menentukan kadar flavonoid terutama golongan flavon dan flavonol (Chang et al., 2002). Baku pembanding yang digunakan adalah kuersetin. Kuersetin merupakan flavonoid golongan flavonol dan paling banyak ditemukan ditanaman (Desmianty et al, 2009). Persamaan regresi yang diperoleh adalah $\mathrm{y}=$ $0,004 \mathrm{x}+0,17$ dengan koefisien relasi $\left(\mathrm{R}^{2}\right)=$ 0,994 .

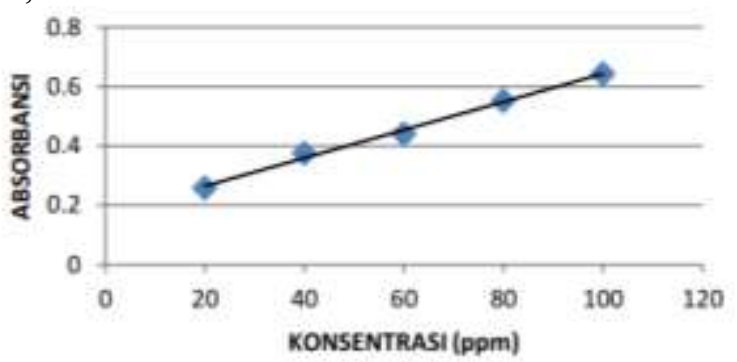

Gambar 4. Kurva Kalibrasi Kuersetin

Hasil uji kuantitatif kadar total fenolik dan kadar total flavonoid ekstrak daun talas menunjukkan bahwa metode ekstraksi berpengaruh signifikan terhadap kadar senyawa yang terdapat dalam ekstrak. Kadar total fenolik dan kadar total flavonoid ekstrak daun talas pada berbagai metode ekstraksi dapat dilihat pada tabel 2 .

Tabel 2. Kadar Total Fenolik dan Kadar Total Flavonoid Ekstrak Daun Talas Pada Beberapa Metode Ekstraksi

\begin{tabular}{lcc}
\hline $\begin{array}{c}\text { Metode } \\
\text { ekstraksi }\end{array}$ & $\begin{array}{c}\text { Kadar Total } \\
\text { Fenolik } \\
\text { (mgGAE/g } \\
\text { ekstrak) }\end{array}$ & $\begin{array}{c}\text { Kadar Total } \\
\text { Flavonoid } \\
\text { (mgKE/g } \\
\text { ekstrak) }\end{array}$ \\
\hline Maserasi & $5,04 \pm 0,02^{\mathrm{a}}$ & $1,84 \pm 0,24^{\mathrm{a}}$ \\
\hline MAE & $5,60 \pm 0,45^{\mathrm{a}}$ & $6,82 \pm 0,11^{\mathrm{b}}$ \\
\hline Sokletasi & $10,39 \pm 0,01^{\mathrm{b}}$ & $12,44 \pm 0,15^{\mathrm{c}}$ \\
\hline Keterangan : Subscript yang berbeda menunjukkan $\boldsymbol{p} \leq \mathbf{0 . 0 5}$
\end{tabular}

Tabel 2 menunjukkan bahwa kadar total fenolik dan kadar total flavonoid tertinggi ditunjukkan pada metode ekstraksi sokletasi. Hasil ini sesuai dengan hasil rendemen yang diperoleh, yaitu rendemen tertinggi pada metode sokletasi. Rendemen menunjukkan efektivitas proses ekstraksi. Semakin besar rendemen yang diperoleh semakin efektif metode ekstraksi yang digunakan. Semakin besar rendemen menunjukkan semakin banyak senyawa yang dihasilkan. Hasil serupa ditunjukkan dalam penelitian Anshari (2018) menyebutkan bahwa ekstraksi sokletasi mampu menghasilkan kadar total senyawa fenolik tertinggi pada ekstrak daun kopi robusta yaitu 23,5 mgGAE/g ekstrak, dibandingkan dengan metode ekstraksi MAE yaitu sebesar 12 mgGAE/g ekstrak dan metode maserasi sebesar $10 \mathrm{mgGAE} / \mathrm{g}$ ekstrak.

Metode sokletasi merupakan metode ekstraksi yang menggunakan pelarut yang selalu baru. Penggunaan pelarut yang selalu baru pada proses ekstraksi sokletasi juga menyebabkan kadar yang lebih tinggi dikarenakan perbedaan konsentrasi antara pelarut dan zat terlarut sehingga sennyawa yang ada didalam sel akan terus keluar (Wazir et al., 2015). Pada metode ekstraksi maserasi dan MAE kadar total senyawa fenolik tidak berbeda signifikan $(p=0,05)$ namun pada kadar total flavonoid berbeda signifikan $(p=$. Metode MAE merupakan metode ekstraksi yang memanfaatkan radiasi gelombang mikro. Peningkatan suhu selama proses MAE mengakibatkan kenaikan proses evaporasi cairan dalam sel dan terjadi peningkatan tekanan. Hal ini memberikan efek perubahan porositas dinding sel. Peningkatan porositas matrik sel biomaterial yang dikombinasikan dengan kenaikan suhu serta tekanan mendorong terjadinya transfer massa. Hal ini menyebabkan kadar senyawa yang dihasilkan pada metode ekstraksi MAE menjadi lebih tinggi dibandingkan metode ekstraksi maserasi

\section{Kesimpulan}

Perbedaan metode ekstraksi berpengaruh signifikan $(\phi<0,05)$ pada kadar total senyawa fenolik dan kadar total senyawa flavonoid ekstrak daun talas (Colocasia esculenta L). Kadar total fenolik dan kadar total flavonoid tertinggi pada metode ekstraksi sokletasi yaitu sebesar 10,39 mgGAE/g ekstrak dan 12,44 mgKE/g ekstrak.

\section{Ucapan Terimakasih}

Ucapan terimakasih disampaikan kepada pihak laboratorium Politeknik Katolik Mangunwijaya Semarang tempat penilitian ini dilaksanakan, serta semua pihak yang ikut serta dalam penelitian ini. 


\section{Daftar Pustaka}

Blainski, B., Lopes, G.C., De Mello, J.C.P., 2013, Application and Analysis of the Folin Ciocalteu Method for the Determination of the Total Phenolic Content from Limonium Brasiliense L, Molecules,18, 6852-6865.

Desmiaty, Y., J. Ratnawati \& P. Andini. 2009. Penentuan Jumlah Flavonoid Total Ekstrak Atanol Daun Buah Merah (Pandanus Conoideus Lamk.) secara Kolorimetri Komplementer. Prosiding Seminar Nasional POKJANAS TOI XXXVI : 1-8

Harborne, J.B. 1987. Metode Fitokimia Penuntun Cara Modern Menganalisis Tumbuhan. Penerbit ITB. Bandung

Ismail, J., Runtuwene, M.R., Fatimah, F. 2012. Penentuan Total Fenolik dan UjiAktivitas Antioksidan Pada Biji dan Kulit Buah Pinang Yaki (Arecavestiaria giseke). Jurnal Ilmiah Sains.

Kumawat, M., Singh, I., Singh, N., Singh, V., Kharb, S. (2012). Lipid Peroxidation And Lipid Profi le In Type II Diabetes Mellitus. Webmed Central. WMC003147:1-10

Lee, K.I., Kim, Y.J., Lee, H.J., and Lee, C.H., 2003, Cocoa Has More Phenolic Phytochemical and Higher Antioxidant Capacity than Theas and Red Wine, J. Agric. Food Chem.
Puspitasari, D.A \& Proyogo, S.D., Perbandingan Metode Ekstraksi Maserasi dan Sokletasi Terhadap Kadar Total Fenolik Total Ekstrak Etanol Daun Kersen (Muntingi calabura). Jurnal Ilmiah Cendekia Eksata. Semarang : Fakultas Farmasi Universitas Wahid Hasyim Semarag.

Ramayani, S. L., Sandiyani, R. P., \& Dinastyantika, V. O. 2000. Kadar Total Fenolik Dan Kadar Total Flavonoid Ekstrak Talas ( Colocasia Esculenta L ). Media Farmasi Indonesia 15(2), 1611-1616.

Richana, Nur, 2012. Ubi Kayu dan Ubi Jalar. Bandung: Nuansa Cendikiawa

Tendean, I. k, Kenta, yunlis silintowe, \& Mulyani, S. 2017. Uji Ekstrak Etanol Daun Talas (Colocasia Escuenta (L) Schott) Terhadap Gambaran Histopatologi Pankreas Tikus Putih Jantan (Rattus Norvegicus) Hiperkolesterolemia Diabetes. Jurnal Farmakologika Farmasi, 14(2), 139-148.

Usman, S. 2019. Pengaruh Metode Ekstraksi Terhadap Rendemen Dan Kadar Fenolik Ekstrak Tanaman Kayu Beta-Beta ( Lunasia Amara Blanco ).Jurnal Farmasi Galenika 5(2), 175-182. https://doi.org/10.22487/j24428744.201 9.v5.i2.13149

Wazir Dayana, dkk., (2015). Antioxidant Activities of Different Parts of Gnetum gnemon L. Journal Plant Biochemistry and Biotechnology. 